The diet must be liquid, and it is better to give frequently and in moderate quantities. Always rinse or wash the mouth after milk, egg, or broth diet, thus preventing the fermentation of particles of food left in the mouth. Do not give the milk pure, but dilute with an alkaline water. Sometimes a drink of hot milk and soda-water will allay the irritation of the cough. (Burney Yeo.) Give water freely and lemonade if desired, and when the patient is delirious give water at fixed intervals. All nourishment and stimulant must be taken slowly. To put a glass to a patient's mouth and allow him to drink even two ounces without rest will retard the rapid respiration and is certain to excite cough.

Consider every case of pneumonia as infectious, but more especially in the epidemic form. Burn the sputa or destroy with a powerful germicide. Do not use handkerchiefs, but rather old linen or butter-cloth, which can be burned at once. Keep the dishes separate and cleanse them by boiling, with soda bicarbonate in the water. In sweeping the room gather the dust with a broom wet in a strong solution of carbolic acid; wipe the furniture with a wet cloth wrung out of carbolic or formalin solution, and carbolize the towels, bed-linen, and patient's clothing.

In handling the patient take great care to aroid the breath, and warn other members of the household to do so. Carefully cleanse your own mouth with an aseptic tooth-paste or wash; remember that the pneumococcus lurks in the mouth of twenty per cent. of all healthy people.

On the recovery or death of the patient have the room, furniture, and clothing at once disinfected and cleansed as you would after the recovery or death from any other infectious disease. With these precautions we may do something to prevent the terrible progress and ravages of pneumonia.

\title{
THE SCIENCE OF THE BREATH
}

\section{BY ISOLETTE JEFEERSON \\ Philadelphia, Pa.}

THE average man uses about one-third, the average woman about one-fifth, of the lung capacity. Children cultivate many bad habits of sitting, walking, standing, and sleeping which are the result of imperfect lung action. Is it not time to revive the almost lost art of correct breathing?

Like the Eastern man who went to California, and when asked 
what kind of orange he preferred replied, "Why, I thought an orange was an orange," most people think that breathing is just breathing, and many will not be told that they do not know how to breathe. The evolutionary process through which we go to become convinced of our ignorance may be long or short, but it is the proverbial beginning of wisdom. Open your eyes and observe the contracted chests, humped shoulders, and slumped abdomens all about you. Do these exist because of weak lungs? No! People have weak and diseased lungs because they hump and sink and slump-in other words, because they do not breathe properly. We have gone too far in wrongly assigning the cause to the result, instead of vice versa.

We have long been vaguely aware that fresh air and deep breathing are important, but are just beginning to awaken to their true meaning. It is one thing to talk and write about these essentials in a general way, it is another to set about teaching them comprehensively. The doctor can say, "Now, take deep breaths and plenty of fresh air;" he seldom does more than say it, and really has not time for more, and the patient promptly forgets all about it, or, if he tries to follow directions, does so in a most ineffectual way. It comes within the province of the nurse to show patients painstakingly how to take the breaths and so how to appropriate the pure air. To do this she must first perfect herself in the science and be able to say, "I have done this and know that it can be done," not, "Go, do this," but, "Come, I will show you how." A few advanced teachers have already engaged in this interesting occupation, and are finding most gratifying response from those who appreciate it, as well as hearty coöperation from many of the medical profession.

You think it is a simple thing. It is. And, listen! The greatest things in the world are the simplest. When we hear of any new discovery and invention we wonder why someone has not thought of it before, it seems so obvious. The wonder is why we do not use our powcrs and organs to their fullest, instead of stupefying and contracting them, or developing a part and allowing the rest to atrophy. But this "science of the breath" is not new. It was the secret of the prophets, was taught in Greece before our era, was practised by the apostles, and has been kept alive by the discerning few of all times and nations. To us it comes from the mystics of the older civilization, and by us it must be made practical and useful. The afflicted of mind and body are waiting for it. The profession of healing is resorting to it more and more every day. It is not a fad, nor is it formidable. Just what it means is the process of appropriating the air we need, coupled with proper bodily development and the right mental attitude. Simple? Yes, and fearfully and wonderfully complex. 
All reasoners acknowledge that thought rules everything. Then surely it rules our individual bodies. So there is the problem of metaphysics-a word, by the way, not generally understood. A good many people shy at it because they think it implies things too deep and abstruse for the average mind-things curious and uncanny, even. Its simple definition is, "the study of mental phenomena." Nothing appears materially until it has first been conceived in thought form. How and what we think, then, determines how and what we produce, whether the work of our hands or of unseen forces manifesting in our bodies. To make a systematic study of our thought power, therefore, is the most thorough and lucid method of governing our results, of assuring success, and of analyzing failure. Applying our conclusions to the everyday, practical things of life is applied metaphysics.

May we govern our health, our business, and our pleasure? Beyond all doubt, in just the proportion that we truly govern our thoughts and achieve all-round self-control. Concentration of thought and willpower form the touchstone. Control of the breath is the keynote.

Now, strong souls have wills, weak ones have only wishes. Shall we wish, or shall we will to be well and clean and whole and strong? Since the body is made out of the blood, and as the blood is composed of the oxygen we breathe and the food we eat, influenced by the mental habit, why not learn how to breathe and eat and think correctly? In this trinity lies the solution of all our difficulties, the remedy for all our ills. We may not yet have evolved to where we can apply it so completely, but therein lies our salvation. And sometime we shall come into our birthright.

A large proportion of people are coming to realize that there is a practicable road to health not paved with drugs and policed by doctors. Is this heresy? Not a bit of it. Many of the most able physicians are recognizing the futility of drugs and applying the higher methods of suggestive therapeutics. For instance, it is scientifically demonstrated that passion materially affects the chemical condition of the blood. Experiments have proven that fear, hate, anger, melancholy, generate poisons in the tissues, which are clearly distinguishable, and these devitalize, destroy, and incapacitate. Professor Gates, of the Smithsonian Institution, says:

"My experiments show that irascible, malevolent, and depressing emotions generate in the system injurious compounds, some extremely poisonous; also that agreeable, happy emotions generate chemical compounds of meritorious value which stimulate the cells to manufacture energy."

Thus are the most scientific and capable practitioners arriving at diagnosis in the relation between the mental and the physical, or the 
Law of Correspondence. Then by analogy we may conclude that since wrong thinking creates disease, right thinking can prevent and cure it, and a healthful attitude of mind ean maintain a corresponding condition of physique. The most advanced and skilful doctor gives the least medicine, and studies and regulates with minute care the mental and moral influences of his patient.

Wc read of continued effort, fresh conviction, and new discoveries along this line of breathing in all the leading journals. Concerning the alarmingly prevalent scourge of all peoples, the burden of white men and black,-pulmonary tubcrculosis,-a recent article in the Scientific American says :

"All efforts to cure the disease by drugs have utterly failed, and it is now admitted that the only thing to be done is to give the patient plenty of fresh air, and adopt strict sanitary measures. As pulmonary tuberculosis is due to imperfect development or unhealthy condition of the lungs, why not makc all children and others immune by teaching them how to breathe properly, thus developing every part of the lungs, and making it impossible for the bacilli to live there? Small or unused lung capacity means low vitality. It would be impossible for a person to contract consumption who completely filled the air-cells of the lungs with pure air. In the incipient stages of the disease breathing exercises will assist greatly in effecting a cure."

And, again, he says: "Common nervous breakdown would seldom occur if the lungs were used as nature intended them to be."

By scientific, controlled breathing shall we gain immunity from consumption, as wcll as many other ills, and this opcns a new line of work for nurses. Instead of devoting all their time and strength to slavishly waiting on the sick, and in many cases increasing their helplessness, they can teach them how to make and keep themselves well. This does not mean in any way an infringement upon the doctors' province, nor does it mean the ignorant and emotional practice of mystic rites, but what can be made the intelligent, useful application of practical knowledge and systematized movements, with a comprehension of some of the forccs beyond the physical or material plane.

A few nurses are already in this field of endeavor and are achieving marked success. They are engaged in working out their own salvation of mind and body, and adding a new dignity to the profession, while lending a hand to the world's work of saving souls and uplifting humanity by healing the minds and correcting the bodies. 